\title{
Condensation Control in Polyhouse using Embedded System
}

\author{
A. J. Hake \\ M.E.S College of Engineering, Pune
}

\begin{abstract}
The development of the crop grown in the greenhouse depends on the internal environment such as air movement, temperature, humidity, $\mathrm{CO}_{2}$ and light. The monitoring and control of this parameter play a vital role in the overall development of the plant, its production and management. Commercially available greenhouse monitoring systems are quite expensive. The Indian poor farmers are unable to deploy this commercial systems. This paper presents a low cost system developed to monitor and control the greenhouse environment. The system is developed using ATMEGA 168 controller Arduino Uno board which is low cost, effective and simple. Various sensors are integrated to this board which monitor and control various parameters. Condensation occurs if temperature and humidity is not maintained properly. This affects the overall growth of plant. Experimental results demonstrates the monitoring and controlling capabilities of the developed system.
\end{abstract}

\section{Keywords:}

Greenhouse, monitoring, control, sensors, automation

\section{INTRODUCTION}

The growth and development of a crop depends on the atmospheric conditions inside a greenhouse. The greenhouse monitors various parameters which helps in the overall development of crops. This green house is built of glass, polythein, polyethylene or net/ shade net that passes sunlight. Various external parameters such has temperature, humidity, $\mathrm{CO}_{2}$ and light depends on the atmospheric conditions. The external atmospheric parameter depends upon the weather conditions. The atmospheric parameters inside the greenhouse are referred as climate. The term climate is not precisely defined, but the conditions that form the greenhouse climate are air, temperature, humidity and radiations. In the green house, the ground gets heated due to sun rays passing through the plastic or glass which falls on the ground. As this ground gets heated, the air temperature inside the greenhouse gets increased.

In the green house, these parameters are artificially controlled which helps in the growth of plant. The parameters which are controlled inside the greenhouse are called as micro climate. The research carried out considers largescale greenhouses which constitute the vast majority of commercial greenhouses. Different mechanisms are used for modelling and controlling of climate inside the greenhouse. Since the pioneering studies of Businger [1]

\author{
A. J. Patil \\ Shri Gulabrao Deokar College of Engineering
}

various greenhouse model have been published.

This micro climate is modelled by different modules and high level automated systems are available for modelling and controlling the climate of green house. This high level systems are quite expensive, which the Indian farmers cant afford it.

The control of humidity and temperature of greenhouse will help in overall development of crops. The use of automatic control technique have increased during the last years in greenhouse monitoring [2, 5]. This paper presents the development of low cost system for controlling the micro climate of greenhouse which is cost effective. The temperature, humidity, light intensity, carbon dioxide $\mathrm{CO}_{2}$ and soil moisture are monitored and controlled as per the requirements of the greenhouse depending upon the type of crops, stage of crop as vegelative, flowering, fruiting. The condensation is avoided in polyhouse which affects the growth of plant.

The remainder of this paper is paper is organized as follows: Section 2 provides the description of the green house model and related work. Detail description of the developed greenhouse monitoring model is given in Section 3 Experimental results and discussions are reported in section 4 Section 5 concludes this paper.

\section{GREENHOUSE MODEL}

The crop grown inside the greenhouse is influenced by the conditions relevant for growth and development inside the greenhouse. This inside relevant conditions are varied by different actuators and the outside conditions which depends upon the greenhouse structure. Inside the greenhouse the climate can be described based on the type of crop and its surrounding local climate. Various models have been illustrated by researchers to control the temperature and humidity of the green house. Fig. 1] shows greenhouse model with various environment parameters.

The cultivation of crops in the greenhouse is very complex issue. This complex issue can be simplified if a data is available which represents the amount of water, temperature, fertilizer etc. required at that movement. The longevity, fertility and development of crops depend upon microclimate. Burnett $[6]$ have shown the growth of plant depends upon the air temperature. Robb et. al. [7] have analysed that the highest longevity can be obtained at $20^{\circ} \mathrm{C}$ and the highest fertility between $20^{\circ}$ and $27.2^{\circ} C$, with an optimum for $27.2^{\circ} C$. Rodriguez [8. 9] have carried deeper study of various climatic control parameters such has temperature, humidity, $\mathrm{CO}_{2}$, 
ventilation etc. on the crop growth as a function of climate environmental conditions. .

\section{DESIGN OF LOW COST GREENHOUSE MONITORING SYSTEM}

TThe greenhouse system is being controlled by different automated systems. This system are categorized as manual, semi-controlled, fully controlled and fully automated with computerized system. In manual controlled system the human operator measures various parameters and the monitor these parameters. In semi-controlled system the human operator adjust few parameters with the measurement being carried out and the decision is being taken by the climate control system. In fully controlled system majority of parameters are controlled by the system. In case of fully automated computerized system, majority of parameters are monitored and controlled on real time based with volume or sensor based technology integrated with computerized process to keep data and records of previous history. The system has minimal human intervention while controlling different parameters. Above system has some limitations. The above systems are more expensive which the Indian farmers cant afford it. Considering Indian farmer potentials and environmental conditions in major farms in India there is a need to develop a low cost and intelligent system, to suit the location, structure, local conditions needs and manpower availability.

An embedded system is designed to monitor humidity, temperature and $\mathrm{CO}_{2}$. The ATMEGA 168 microcontroller is used easily available in Indian market and replacement in case of failure is easier. This board is integrated with various sensor which is the heart of the system. Fig. 2 shows the schematic of the ATMEGA 168 UNO board

In order to control various parameters inside the greenhouse different sensors are integrated to this microcontroller. The block diagram of greenhouse monitoring system is shown in Fig. 3

Various sensors [10-12] have been used for monitoring temperature, humidity, $\mathrm{CO}_{2}$ and soil moisture. This sensors modules have been selected based on the requirement of the parameters to be monitored .

Temperature and humidity measurement is carried out using DHT22 sensor manufactured by Aosong electronics Co ltd. This is a capacitive sensor with temperature sensor built in along with interface electronics circuit for microcontroller interface.

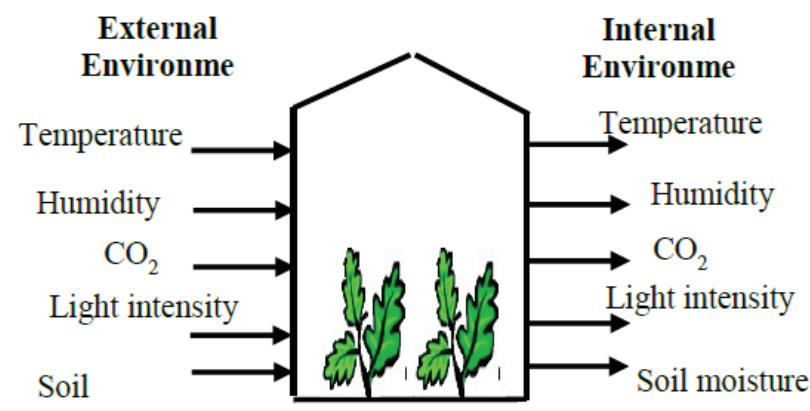

Fig. 1. Greenhouse environment

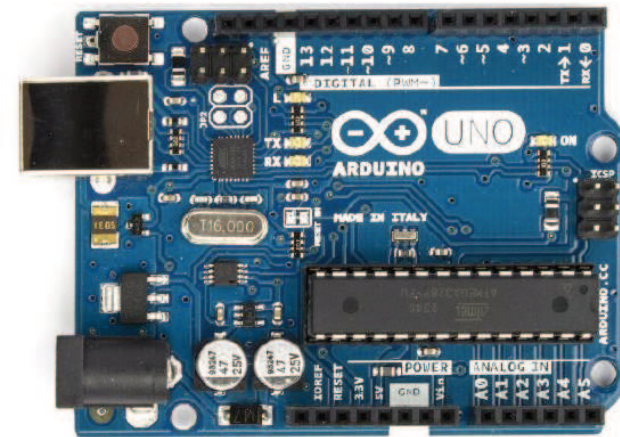

Fig. 2. Arduino Uno board

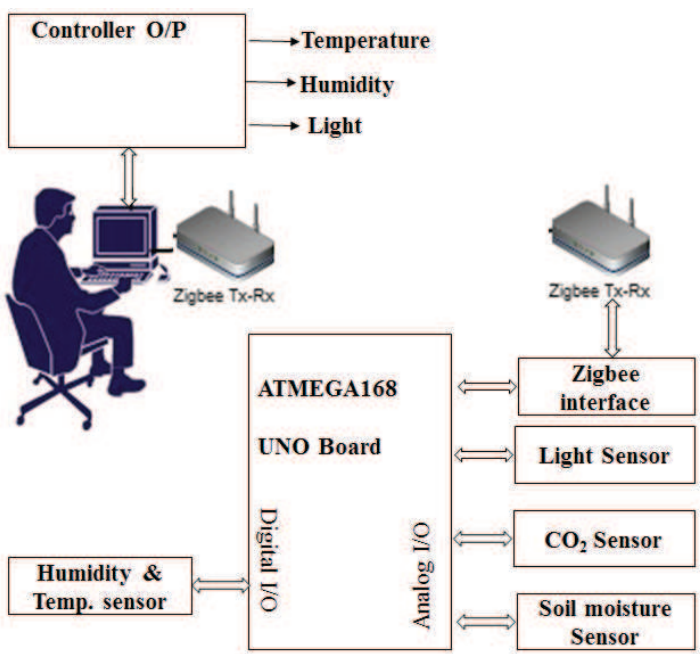

Fig. 3. Block diagram of greenhouse monitoring system

Light intensity is being measured by light sensor $B H 1750$ which is mounted inside and outside of green house. This sensor can also be directly integrated with the ATMEGHA UNO board. $M G-811 \mathrm{CO}_{2}$ [6] sensor module is used for $\mathrm{CO}_{2}$ gas sensing. The signals received from this sensors are further processed by signal conditioning unit and the interfaced to the board. VH400 sensor is used to check soil moisture. The interface circuit gives output in analog form which is connected to the board.

The received data from these sensors on the board is transmitted using wireless Zeegbee protocol [13] to the monitoring station. This data is also received by controller which activates actuators to control humidity, temperature, light intensity, $\mathrm{CO}_{2}$ and soil moisture. The need of control system is to control the parameter on either side as increase or reduce.

System design approach is with Indian conditions. Thus first as poly house structure is developed for test purpose the various parameters outside and inside are measured and strategy is planned for control.

For humidity control a fogger/mister is used to increase humidity. To reduce humidity the ventilator/exhaust is operated when outside humidity lower. For temperature fan pad system is to reduce the 
temperature or ventilator is operated to bring outside air to reduce the temperature. While controlling temperature humidity gets affected needs correction accordingly. Light intensity if exceeds the desired limit the net shade is activated to cover the crop , artificial light is not used for any of the purpose and light is available for most of the time in most of the parts of the country. $\mathrm{CO}_{2}$ is monitored and the data is recorded by observation it is found that there is no separate need of $\mathrm{CO}_{2}$ generator. Soil moisture is one of the important parameter need to control by dripper, the need to run the dripper is also based on sun light and humidity needs. The logical flow is designed for this control and empirical setting need based on structure and location of the polyhouse.

\section{EXPERIMENTAL RESULTS}

In spite of fruitful study, various control systems were discuss to length. Still there is scope for further improvement and develop controller system to suit the requirements.

There are various observations while measuring parameters as direct sun light on sensor, shadow of tree nearby, wind flow , cloudy weather etc. affects the sensor signal hence need to be located at appropriate location outside and inside poly house. The Fig. 4 shows experimental set up in side test house this was for initial preparation and testing of circuit.

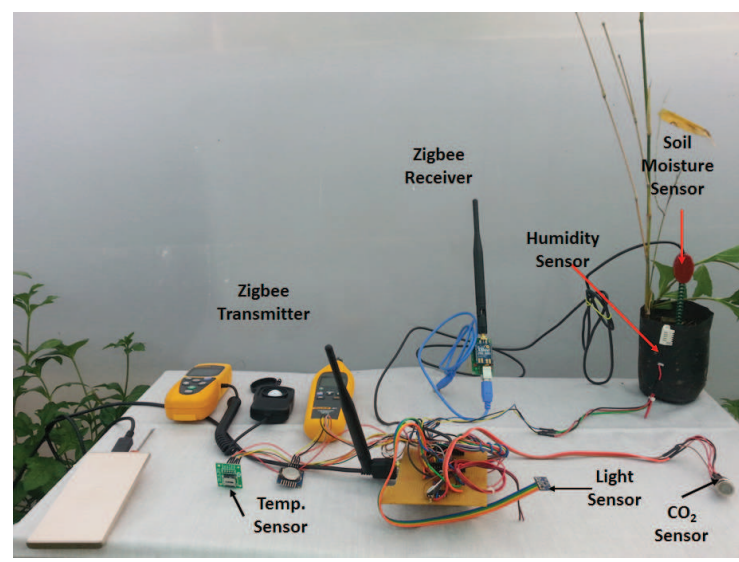

Fig. 4. Polyhouse experimental setup

Environment parameters such as light intensity, $\mathrm{CO}_{2}$, humidity and temperature are measured in three different conditions i.e. outside polyhouse, inside polyhouse without control and inside control polyhouse with control. The values obtained for different conditions are presented in Fig. 5 to Fig. 8 It was observed that this helps in understanding the need of setting up control system. The location of poly house, orientation as North -South, East-West, season, size etc matters. Thus parameters outside and inside poly house as temperature, humidity, sun light are measured . Initially when crop is in growing phase the temperature and humidity needs are different than when it is flowering stage.

If the light intensity increases above set value 4000 lux then net filter is used to reduce the light intensity. Fig. 5 shows the readings of light intensity outside test poly house, inside test poly house with out control system and control system with set points.

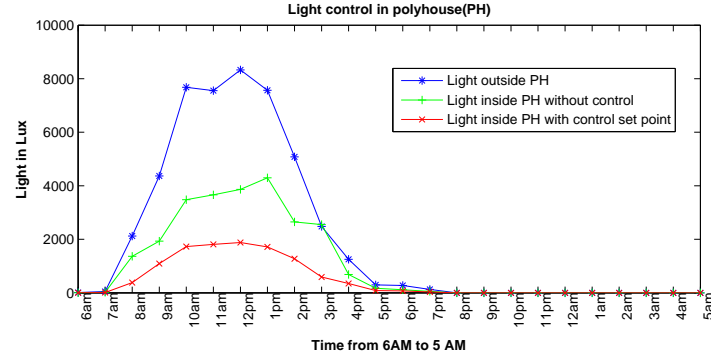

Fig. 5. Light variations in polyhouse

The photosynthesis process is more active during the day time when the light intensity is more than 3000 lux. During this period adequate availability of $\mathrm{CO}_{2}$ boosts the photosynthesis process. This photosynthesis process is necessary for growth of plant and yield. Due to this reason $\mathrm{CO}_{2}$ is monitored and control from 9 A.M. to 5 P.M. with the set range of 500-900 ppm. Based on the age of plant in this research the $\mathrm{CO}_{2}$ value is set to 550ppm. Fig. 6 shows the readings of $\mathrm{CO}_{2}$ outside test poly house, inside test poly house with out control system and control system with set points.

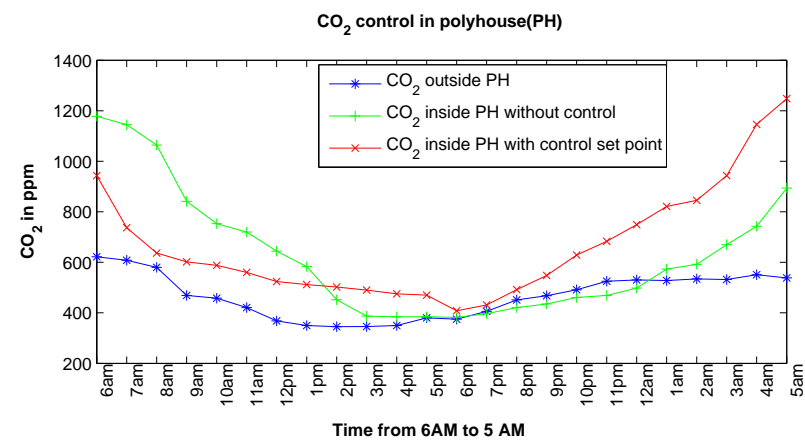

Fig. 6. $\mathrm{CO}_{2}$ variations in polyhouse

The control of humidity is a typical, needs series of adjustments to set up closer to set value. The watering and drip irrigations also need careful settings, which indirectly affects humidity. The sun light if directly reaching soil affects temperature inside directly, need good cooling system arrangement to control temperature. If temperature is reduced the humidity also reduced. Humidity at roof or canopy is more than it is closer to crop or leaf surface. If temperature increases humidity also increases. If humidity is low plant requires more water to maintain the lead surface temperature and if it is high it results into fungal growth on the leaf surface. If humidity is maintained between $50-70 \%$, it helps in growth of plant. In this experiment humidity is set to $70 \%$. Fig. 7 present shows different humidity readings outside test poly house, inside test poly house with out control system and control system with set points which are controlled by developed system.

In the polyhouse the temperature is measured using Temperature sensor. Temperature in polyhouse is controlled with the help of ventilators, fan and pad cooling arrangement. The Fig. 8 shows the temperature value which are measured in three different conditions. 


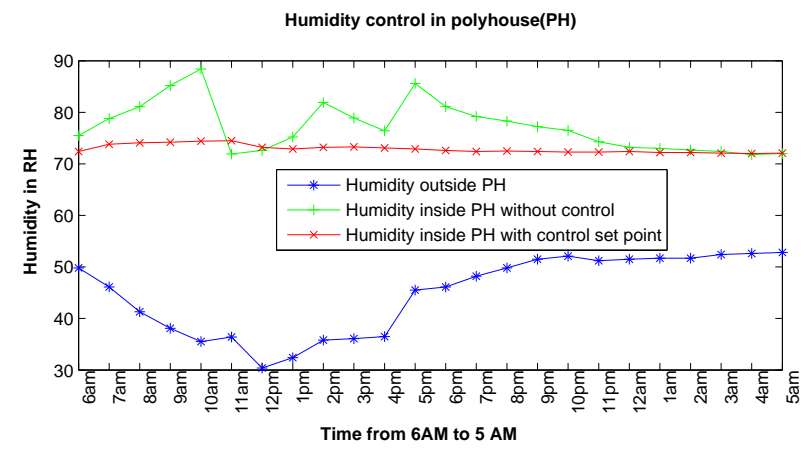

Fig. 7. Humidity variations in polyhouse

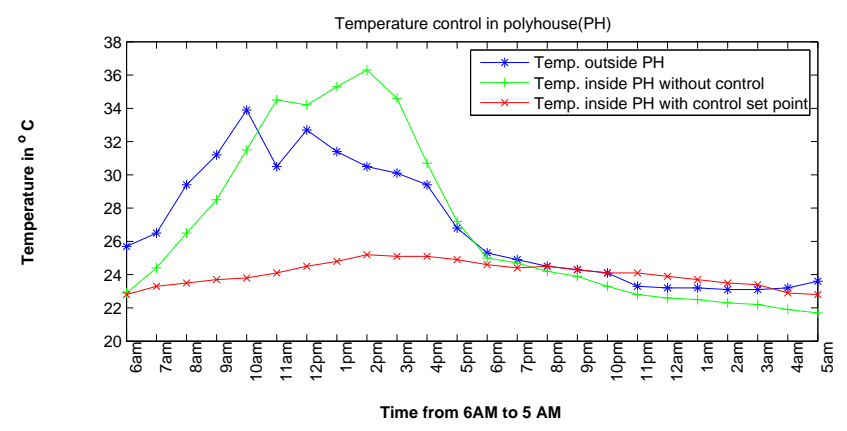

Fig. 8. Temperature variations in polyhouse

The above experimental results shows the results are close to set values with a tolerance limit of $\pm 5 \%$ or less. If the humidity and temperature is not monitored in the polyhouse then condensation occurs which hampers the growth of the plant.

\section{CONCLUSIONS}

The ploy house /greenhouse parameter monitor and control system for desired conditions is implemented. The sensor devices available are integrated with Microcontroller board with stack-able slot for wireless or other modules is very useful. The setting needs series of observations and study inter dependency of various parameters, such as temperature, humidity and sun light intensity. Arduino board make it easy to install and maintain the system.

The system deployment in test poly house is studied implies need of poly house structures study, inside, outside environment study, crop needs etc. Simply controlling given parameters is not enough. The experimental results demonstrates that the growth of plant is increased by $20 \%$ in the control environment. A low cost embedded system is developed to measure and monitor polyhouse environment. The wireless model needs as DC supply can be given in the form of a battery bank easy to charge with solar system. There are limitation in terms of seasonal measurements and crop needs. The user awareness of how to check system operation is a basic need to be fulfil.

Based on the experiments there is a scope for sensor developments, which can be easy to replace and calibrate. The plug and self-install system models are a necessity.

\section{REFERENCES}

[1] J. A. Businger, The glasshouse climate, physics of plant environment, North Publ. Co., Amsterdam, 1963.

[2] G. Straten, What can systems and control theory do for agriculture?, in: Proceedings of 2nd IFAC International Conference Agricontrol, Osijek, Croatia, 2007.

[3] I. Farkas, Modelling and control in agricultural processes, Comput. Electron. Agric. 49 (8) (2001) 315-316.

[4] N. Sigrimis, P. Antsaklis, P. Groumpos, Special issue on control advances in agriculture and the environment, IEEE Control Syst. Mag. 21 (2001) 78-85.

[5] N. Sigrimis, R. King, Special issue on advances in greenhouse environment control, Comput. Electron. Agric. 26 (1999) 217-374.

[6] T. Burnett, The effect of temperature of an insect hostparasite population, Ecology, (1949) 113-133.

[7] K. L. Robb, M. P. Parrella, Towards understanding the thysanoptera, General Technical Report NE147, US (1991) 343-358.

[8] F. Rodriguez, Modeling and hierarchical control of greenhouse crop production, $\mathrm{PhD}$ thesis, University of Almera, Spain.

[9] F. Rodrguez, J. L. Guzmn, Adaptive hierarchical control of greenhouse crop production, Int. J. Adap. Cont. Signal Process 22 (2008) 180-197.

[10] N. Wang, N. Zang, Wireless sensors in agriculture industryrecent development and future perspective, Computers and Electronics in Agriculture 50 (2006) 1-14.

[11] S. Shanmugantah, A. Ghobakhlou, P. Sallis, Sensor data acquisition for climate change modelling, WSEAS Transactions on Circuits and Systems 7 (2008) 942-958.

[12] J. Burrell, T. Brooke, R. Beckwith, Vineyard computing: Sensor networks in agricultural production, Sensor and Actuator Network 7 (2004) 38-45.

[13] R. Morais, M. Fernandes, S. M. et. al., A zigbee multipowered wireless acquisition device for remote sensing applications in precision viticulture, Computers and Electronics in Agriculture 62 (2008) 94-106. 